\title{
Study on mechanism of mercury oxidation by fly ash from coal combustion
}

\author{
ZHAO YongChun ${ }^{1}$, ZHANG JunYing ${ }^{1 *}$, LIU Jing $^{1}$, DIAZ-SOMOANO Mercedes ${ }^{2}$, \\ MARTINEZ-TARAZONA M. Rosa ${ }^{2} \&$ ZHENG ChuGuang ${ }^{1}$ \\ ${ }^{1}$ State Key Laboratory of Coal Combustion, Huazhong University of Science \& Technology, Wuhan 430074, China; \\ ${ }^{2}$ Instituto Nacional del Carbón (CSIC), Francisco Pintado Fe 26, 33011, Oviedo, Spain
}

Received July 5, 2009; accepted July 28, 2009

\begin{abstract}
To understand the interaction of fly ash and mercury, systematic experiments on mercury oxidation in single flue gas composition are conducted on a fixed bed reactor system, the desorption rate and speciation of mercury are valuated. The results indicate that fly ash itself can significantly promote elemental mercury oxidation. A classification of fly ash activated sites is developed according to the speciation of mercury during adsorption-desorption tests, the reaction mechanism of mercury oxidation by fly ash is proposed. Acid gas can promote mercury oxidation and improve the stability of oxidation product. Lattice oxygen is an important oxidant of mercury oxidation.
\end{abstract}

mercury, fly ash, oxidation, adsorption-desorption, flue gas

Citation: $\quad$ Zhao Y C, Zhang J Y, Liu J, et al. Study on mechanism of mercury oxidation by fly ash from coal combustion. Chinese Sci Bull, 2010, 55: 163-167, doi: $10.1007 / \mathrm{s} 11434-009-0567-7$

Study on emission and control of mercury is one of the hot issues recently [1-10]. The partition and interaction of mercury and flue gas, as well as fly ash particles during coal combustion have significant influence on its distribution, emission and control [1]. The characters of fly ash and interaction with flue gas have an important impact on mercury heterogeneous oxidation [2]. The heterogeneous interaction of fly ash-flue gas-mercury is complex because of the complexity of flue gas compositions and fly ash components. Previous studies investigated the effect of acid gas including $\mathrm{Cl}_{2}, \mathrm{HCl}, \mathrm{SO}_{x}, \mathrm{NO}_{x}$, etc. on mercury catalytic removal [2-5], but less concerned about other components such as $\mathrm{O}_{2}, \mathrm{CO}_{2}$, and $\mathrm{H}_{2} \mathrm{O}$, which were generally considered to have little effect or no effect on $\mathrm{Hg}^{0}$ oxidation [3]. Besides, the report about intrinsic properties of fly ash on mercury oxidation is rare. Considering the characteristic of fly ash, the contained unburned carbon and activated inorganic components are the key factors of mercury adsorption and oxidation [6-9].

*Corresponding author (email: jyzhang@mail.hust.edu.cn)
However, the interaction of fly ash and mercury is still not clear until now. Presto et al. suggest that there are two types of activated sites on the surface of sorbent for mercury: One is stable activated site with higher binding energy between mercury and sorbent, mainly used to capture mercury; the other is catalytic activated sites that can also capture mercury, but its binding energy is low and mercury is easy to re-release from the sorbent, this type of activated sites is just for catalytic oxidation of $\mathrm{Hg}^{0}$ [11]. This concept explains the difference between adsorption activated site and oxidation activated site, however, this classification is not comprehensive. To understand the detailed interaction mechanism of mercury and fly ash, systematic mercury adsorption-desorption experiments are carried out on a fixed bed reaction system, the interaction between fly ash and mercury with common flue gas components is discussed, and the distribution of mercury species during adsorptiondesorption process is investigated, which provide the basis for clarifying the mechanism of mercury oxidation by fly ash. 


\section{Experimental section}

The experimental device used for the mercury capture experiments at the laboratory scale consisted of a glass reactor fitted with an internal tube and external tube, and heated by a furnace (Figure 1). The mercury permeation tube was put into a U-tube inside the constant temperature water tank to generate gaseous mercury. The gaseous mercury was carried by nitrogen and then mixed with air before passing the sorbent bed. The flow was $0.5-1 \mathrm{~L} / \mathrm{min}$. The sorbent was composed by $0.5 \mathrm{~g}$ fly ash mixed with $1.5 \mathrm{~g}$ sand, and then was put into the internal tube. The height of the sorbent bed was about $3 \mathrm{~mm}$, and the temperature was $120^{\circ} \mathrm{C}$. A continuous emission monitor (UT3000) was used to measure mercury concentration at the outlet of the reactor, and the Ontario Hydro impinger was used to analyze mercury speciation, the waste gas was adsorbed by chemical solutions. Fly ash samples were collected from electrostatic precipitator ash bucket of power plant which burns typical bituminous coal in Spain (SPA). Duplicate tests were conducted in different atmospheres and conditions to get the average value.

\section{Results and discussions}

\subsection{Homogeneous oxidation in different atmospheres}

The fly ash-flue gas-mercury gas solid reactions are complex. To exclude the effects of flue gas compositions, know the detailed mechanism of mercury oxidation by fly ash, the systematic homogeneous oxidation of mercury in different flue gas compositions was conducted, the results are shown in Figure 2. There is no obvious homogeneous oxidation for $\mathrm{Hg}^{0}$ at $120^{\circ} \mathrm{C}$ in different atmospheres, even with $33 \mathrm{ppm}$ $\mathrm{HCl}$. Widmer investigated the influence of $\mathrm{HCl}$ on $\mathrm{Hg}^{0}$ oxidation, and they found that high mercury oxidation rate only obtained at high temperature and high $\mathrm{HCl}$ concentration [12]. Laudal et al. suggested that $\mathrm{Cl}_{2}$ was the main oxidant of $\mathrm{Hg}^{0}$ in low temperature flue gas [3]. Therefore, there is no homogeneous oxidation of mercury under all kinds of atmospheres in this experimental system.

\subsection{Heterogeneous oxidation of mercury by fly ash}

Mercury oxidation tests by SPA fly ash in three typical atmospheres $\left(\mathrm{N}_{2}\right.$, Air, and $\left.\mathrm{HCl}\right)$ were conducted and lasted for 20 h. As shown in Figure 3, fly ash promoted $\mathrm{Hg}^{0}$ oxidation during the capture process of mercury. The $\mathrm{Hg}^{0}$ oxidation rate of SPA fly ash ranges from $3.1 \%$ to $18.6 \%$ in three atmospheres. $\mathrm{HCl}$ is the most important factor of $\mathrm{Hg}^{0}$ oxidation, however, the influence of $\mathrm{O}_{2}$ should not be ignored. Hall et al. found $\mathrm{O}_{2}$ promoted $\mathrm{Hg}^{0}$ oxidation in their early study [13]. It is worth to mention that SPA fly ash also showed a certain degree of $\mathrm{Hg}^{0}$ oxidation in the $\mathrm{N}_{2}$ atmosphere.

To validate the oxidation of $\mathrm{Hg}^{0}$ by fly ash, the fly ashes after adsorbing mercury in these three atmospheres were used to conduct desorption tests. Desorption tests were carried out in an inert atmosphere lasted for $3 \mathrm{~h}$, and the temperature was set as $180^{\circ} \mathrm{C}$. The desorption amount of mercury from these three fly ashes ranges from $15 \%$ to $25 \%$ (Figure 4), which is less than that from activated carbon sorbent [14], this indicates that mercury on fly ash has relatively good stability. Comparing these fly ashes got in different atmospheres, the desorption rate from fly ash in $\mathrm{N}_{2}$ is similar to that in Air, and both of them are more than that from fly ash in $\mathrm{HCl}$, which illustrates that the interaction between fly ash and mercury is more stable with the occurrence of $\mathrm{HCl}$.

The desorption mercury species vary from fly ashes in

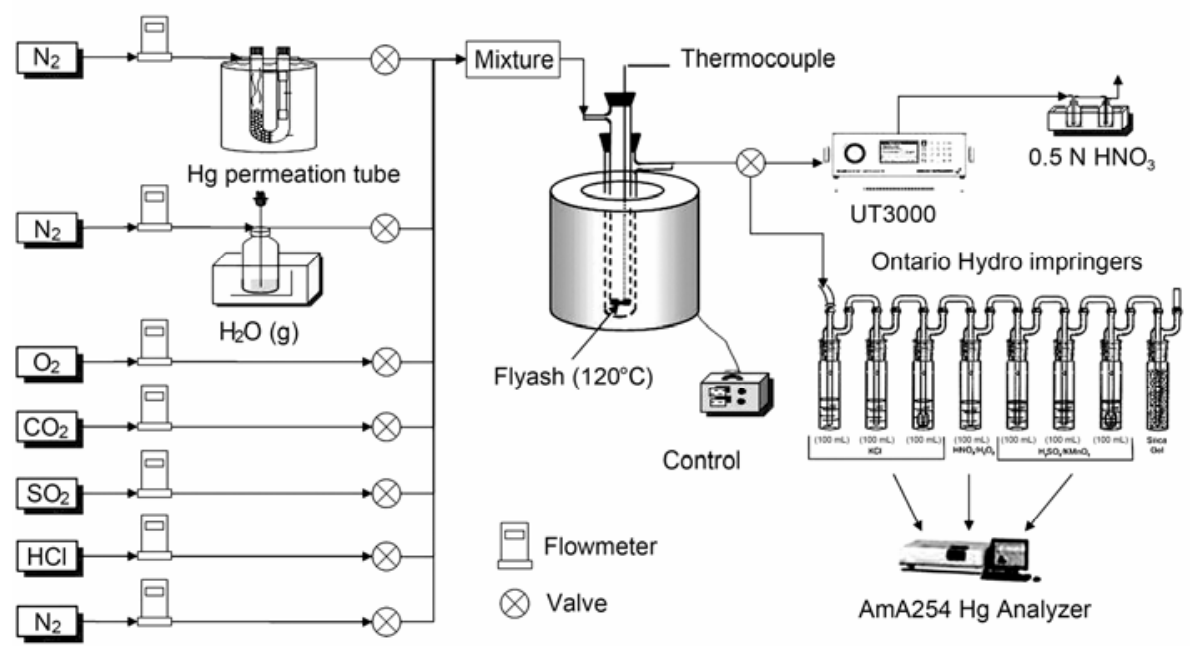

Figure 1 Schematic diagram of mercury adsorption fixed bed system. 


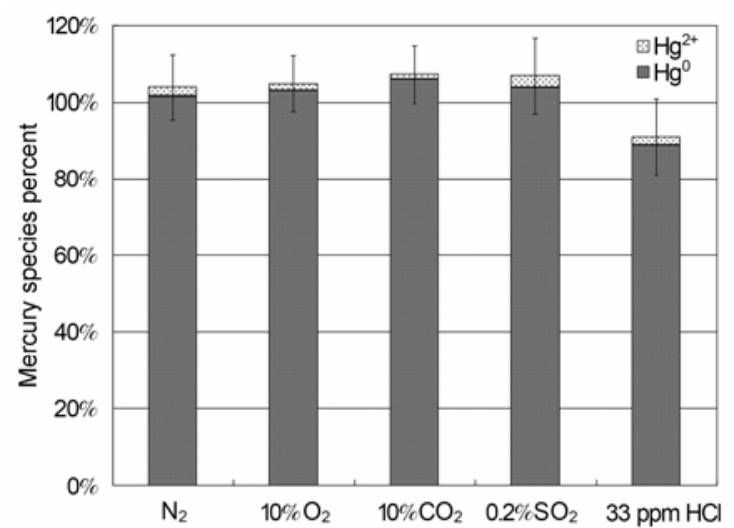

Figure 2 Homogeneous oxidation of mercury in different atmospheres.

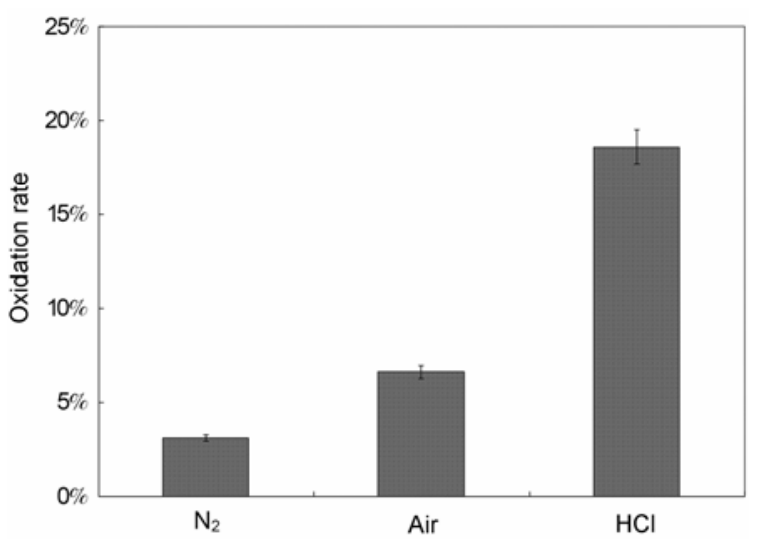

Figure 3 Mercury oxidation by fresh SPA fly ash in different atmospheres.

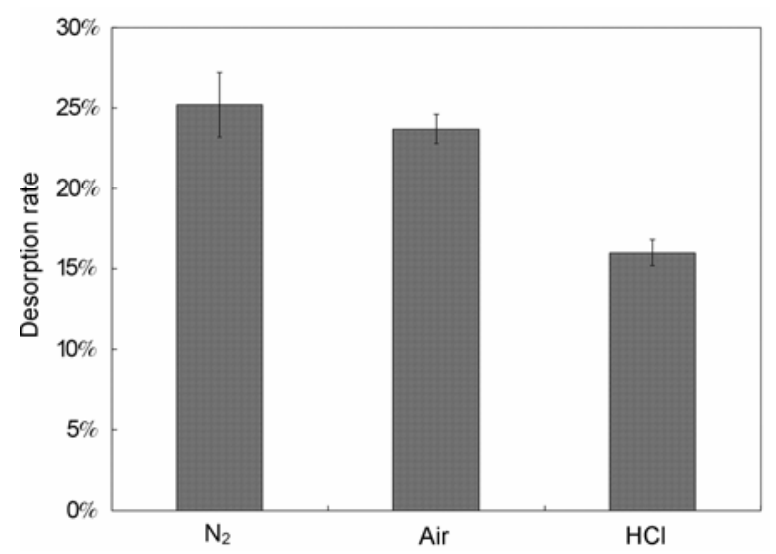

Figure 4 Desorption rates of fly ashes in $\mathrm{N}_{2}\left(180^{\circ} \mathrm{C}\right)$.

three atmospheres. Almost all of the mercury released from the fly ash in Air and $\mathrm{HCl}$ are $\mathrm{Hg}^{2+}$, while mercury released from the fly ash in $\mathrm{N}_{2}$ contains about $50 \% \mathrm{Hg}^{0}$ and $\mathrm{Hg}^{2+}$ (Figure 5). Although the $\mathrm{Hg}^{2+}$ concentration in flue gas after passing the sorbent is not so high in $\mathrm{N}_{2}$, the released $\mathrm{Hg}^{2+}$ during desorption of this fly ash occupied about $7 \%$ of the total mercury in the inlet, which validates that fly ash itself can oxidize $\mathrm{Hg}^{0}$, even in $\mathrm{N}_{2}$.

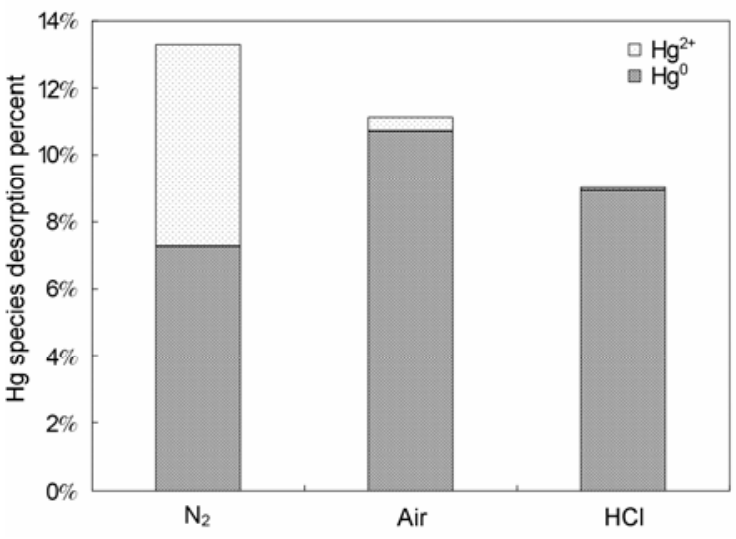

Figure 5 Percent of desorption mercury species in different atmospheres $\left(180^{\circ} \mathrm{C}\right)$.

\subsection{Interaction mechanism of fly ash and mercury}

The oxidation of mercury happened simultaneously with the capture of mercury by fly ash. To understand the detailed interaction mechanism of mercury and fly ash, mercury species generated during adsorption-desorption process were classified as follows:

(i) $\mathrm{Hg}^{2+}$ in adsorption process: similar to the $\mathrm{Hg}^{2+}$ from the oxidation by catalytic activated sites proposed by Presto et al. ${ }^{[15]}$. This kind of activated sites is called low binding energy catalytic oxidation active sites-FA(1);

(ii) $\mathrm{Hg}^{2+}$ released during desorption process: the active sites that generate this $\mathrm{Hg}^{2+}$ can oxidize $\mathrm{Hg}^{0}$, and the binding energy is higher. So this type of active sites is called catalytic oxidation active sites-FA(2);

(iii) $\mathrm{Hg}^{0}$ released during desorption process: the active site combined with this $\mathrm{Hg}^{0}$ only adsorbed $\mathrm{Hg}^{0}$, no catalytic oxidation happened on this site. So this type of active sites is called adsorption active sites-FA(3);

(iv) Residual mercury in fly ash after desorption: this kind of active sites is similar to the high binding energy active sites described by Presto et al., which can be called high binding energy adsorption active sites-FA(4).

Distribution of mercury species during adsorptiondesorption process in different atmospheres is listed in Table 1 . The contents of mercury species vary in different atmospheres, and the total $\mathrm{Hg}^{2+}$ in flue gas during adsorption-desorption process in three atmospheres is $\mathrm{N}_{2}, 10.3 \%$; Air, $16.8 \%$; and $\mathrm{HCl}, 27.5 \%$, respectively.

The content of type (I) mercury in $\mathrm{HCl}$ is the highest, which means the key point of $\mathrm{Hg}^{0}$ oxidation is the oxidant adsorbed on the surface of sorbent. This indicates that the interaction between low binding energy catalytic oxidation active sites FA (1) and mercury is according to Langmuir-Hinshelwood mechanism. Specific reactions are shown in the following eqs. (1)-(4). As the oxidant of $\mathrm{Hg}^{0}$, the adsorption capacity of $\mathrm{HCl}$ on FA(1) is the strongest, then follows $\mathrm{O}_{2}$, while $\mathrm{N}_{2}$ has no oxidation capacity. So the content of $\mathrm{Hg}^{2+}$ is the highest in $\mathrm{HCl}$ atmosphere. 
Table 1 Mercury speciation during adsorption-desorption process in different atmospheres

\begin{tabular}{lcccc}
\hline & $\mathrm{Hg}^{2+}$ in adsorption process & $\mathrm{Hg}^{2+}$ released during desorption process & $\mathrm{Hg}^{0}$ released during desorption process & $\begin{array}{l}\text { Residual mercury in fly ash after } \\
\text { desorption }\end{array}$ \\
\hline $\mathrm{N}_{2}$ & $3.0 \%$ & $7.3 \%$ & $6.0 \%$ & $39.4 \%$ \\
$\mathrm{Air}$ & $6.1 \%$ & $10.7 \%$ & $0.4 \%$ & $36 \%$ \\
$\mathrm{HCl}$ & $18.6 \%$ & $8.9 \%$ & $0.1 \%$ & $47.4 \%$ \\
\hline
\end{tabular}

$$
\begin{gathered}
\mathrm{Hg}^{0}(\mathrm{~g})+\mathrm{FA}(1) \rightarrow \mathrm{Hg}^{0}(\text { ads })+\mathrm{FA}(1) \\
\mathrm{B}(\mathrm{g})+\mathrm{FA}(1) \rightarrow \mathrm{B}(\text { ads })+\mathrm{FA}(1) \\
\mathrm{Hg}^{0}(\text { ads })+\mathrm{B}(\text { ads })+\mathrm{FA}(1) \rightarrow \mathrm{Hg}^{2+} \mathrm{B}(\text { ads })+\mathrm{FA}(1) \\
\mathrm{Hg}^{2+} \mathrm{B}(\text { ads })+\mathrm{FA}(1) \rightarrow \mathrm{Hg}^{2+} \mathrm{B}(\mathrm{g})+\mathrm{FA}(1)
\end{gathered}
$$

The contents of type (II) mercury in three atmospheres are similar. But it should be mentioned that a considerable amount of $\mathrm{Hg}^{2+}$ was generated in $\mathrm{N}_{2}$ atmosphere, even $\mathrm{N}_{2}$ is not the oxidant of mercury. This implies that the oxidant comes from fly ash itself, and fly ash components can oxidize $\mathrm{Hg}^{0}$ directly. This oxidation reaction is according to Mars-Maessen reaction mechanism. Oxygen atom in fly ash components was the same as the oxidant of mercury, when gaseous mercury passing the sorbent bed, it was captured by active site FA(2), then oxidized by active oxygen atom to form $\mathrm{Hg}^{2+}$ (eq. (6)). Previous studies have indicated inorganic metal oxides in fly ash have significant mercury oxidation capacity $[16,17]$. And the sorbent itself can be oxidized with the occurrence of oxygen in flue gas (eq. (7)), then combines with $\mathrm{HgO}$ to form stable binary oxides (eq. (8)).

$$
\begin{gathered}
\mathrm{Hg}_{(\mathrm{g})}+\mathrm{FA} \rightarrow \mathrm{Hg}_{(\mathrm{FA})} \\
\mathrm{Hg}_{(\mathrm{FA})}+\mathrm{M}_{x} \mathrm{O}_{y} \rightarrow \mathrm{HgO}_{(\mathrm{FA})}+M_{x} \mathrm{O}_{y-1} \\
\mathrm{HgO}_{(\mathrm{FA})}+\mathrm{M}_{x} \mathrm{O}_{y-1}+1 / 2 \mathrm{O}_{2(g)} \rightarrow \mathrm{HgO}_{(\mathrm{FA})}+M_{x} \mathrm{O}_{y} \\
\mathrm{HgO}_{(\mathrm{FA})}+\mathrm{M}_{x} \mathrm{O}_{y} \rightarrow \mathrm{HgM}_{x} \mathrm{O}_{y+1}
\end{gathered}
$$

Type (III) mercury is only found in $\mathrm{N}_{2}$ atmosphere, while there is almost no $\mathrm{Hg}^{0}$ released from fly ash in $\mathrm{O}_{2}$ and $\mathrm{HCl}$ atmosphere. This implies that the adsorbed $\mathrm{Hg}^{0}$ was oxidized to $\mathrm{Hg}^{2+}$ in $\mathrm{O}_{2}$ and $\mathrm{HCl}$ atmosphere, and the oxidation reaction followed Eley-Rideal mechanism (eqs. (9)) [15]. The adsorption active sites FA(3) can also adsorb $\mathrm{O}_{2}$ and $\mathrm{HCl}$ easily as oxidant, and then oxidize $\mathrm{Hg}^{0}$ which has been adsorbed following Langmuir-Hinshelwood mechanism. The adsorption active site FA(3) is similar to low binding energy catalytic oxidation active site FA(1), but has a higher binding energy with mercury.

$$
\begin{gathered}
\mathrm{Hg}^{0}(\mathrm{~g})+\mathrm{FA}(3) \rightarrow \mathrm{Hg}^{0}(\text { ads })+\mathrm{FA}(3) \\
2 \mathrm{Hg}^{0}(\mathrm{ads})+\mathrm{O}_{2} \rightarrow 2 \mathrm{HgO} \text { (ads) }
\end{gathered}
$$

$$
\mathrm{Hg}^{0}(\mathrm{ads})+2 \mathrm{HCl} \rightarrow \mathrm{HgCl}_{2}(\mathrm{ads})+2 \mathrm{H}^{+}
$$

Type (IV) mercury remained in fly ash has a high binding energy with FA(4). It can be speculated that this mercury mainly occurs as $\mathrm{Hg}^{2+}$ in fly ash, even no direct evidence was found. The content of type (IV) mercury is higher in fly ash from $\mathrm{HCl}$ atmosphere than that from $\mathrm{N}_{2}$ and air atmospheres, which implies that the interaction of fly ash, $\mathrm{HCl}$, and mercury can be easily combined to form stable $\mathrm{Hg}^{2+}$. Comparing with the fly ash from air, the fly ash from $\mathrm{N}_{2}$ has more residual mercury. This is because the oxidant in $\mathrm{N}_{2}$ is lattice oxygen atom which has a higher binding energy with $\mathrm{Hg}$ than that of $\mathrm{O}_{2}$ - the oxidant in air.

\section{Summary}

The mercury oxidation rate by fly ash in three typical atmospheres $\left(\mathrm{N}_{2}, \mathrm{Air}, \mathrm{HCl}\right)$ ranges from $10.3 \%$ to $27.5 \%$, and all of them are heterogeneous oxidation. The heterogeneous oxidation of mercury mainly includes adsorption oxidation and direct heterogeneous oxidation. The oxidant of adsorption oxidation can be flue gas composition or lattice oxygen atom. While the direct heterogeneous oxidation process is the reaction between the adsorbed mercury and flue gas component on fly ash surface. The active sites on fly ash surface can be classified into four types: low binding energy catalytic oxidation active sites, catalytic oxidation active sites, adsorption active sites, and high binding energy adsorption active sites. Three reaction mechanisms of fly ash and mercury are proposed, the lattice oxygen atom is an important oxidant for mercury, and the oxidation of mercury by fly ash itself is according to Mars-Maessen mechanism.

This work was supported by the National Natural Science Foundation of China (Grant Nos. 50906031, 50721005, 20877030), National Basic Research Program of China (Grant No. 2006CB200304) and China Postdoctoral Science Foundation Funded Project.

1 Gale T K, Lani B W, Offen G R. Mechanisms governing the fate of mercury in coal-fired power systems. Fuel Process Technol, 2008, 89: 139-151

2 Agarwal $\mathrm{H}$, Stenger $\mathrm{H} \mathrm{G}, \mathrm{Wu} \mathrm{S}$, et al. Effects of $\mathrm{H}_{2} \mathrm{O}, \mathrm{SO}_{2}$, and $\mathrm{NO}$ on Homogeneous $\mathrm{Hg}$ oxidation by $\mathrm{Cl}_{2}$. Energy Fuels, 2006, 20: 1068-1075

3 Laudal D L, Brown T D, Nott B R. Effects of flue gas constituents on mercury speciation. Fuel Process Technol, 2000, 65-66: 157-165 
4 Agarwal H, Romero C E, Stenger H G. Comparing and interpreting laboratory results of $\mathrm{Hg}$ oxidation by a chlorine species. Fuel Process Technol, 2007, 88: 723-730

5 Zhao Y, Mann M D, Olson E S, et al. Effects of sulfur dioxide and nitric oxide on mercury oxidation and reduction under homogeneous conditions. J Air Waste Manag Assoc, 2006, 56: 628-635

6 Lopez-Anton M A, Abad-Valle P, Diaz-Somoano M, et al. The influence of carbon particle type in fly ashes on mercury adsorption. Fuel, 2009, 88: 1194-1200

7 Lu Y, Rostam-Abadi M, Chang R, et al. Characteristics of fly ashes from full-scale coal-fired power plants and their relationship to mercury adsorption. Energy Fuels, 2007, 21: 2112-2120

8 Dunham G E, DeWall R A, Senior C L. Fixed-bed studies of the interactions between mercury and coal combustion fly ash. Fuel Process Technol, 2003, 82: 197-213

9 Galbreath K C, Zygarlicke C J, Tibbetts J E, et al. Effects of $\mathrm{NO}_{x}$, $\alpha-\mathrm{Fe}_{2} \mathrm{O}_{3}, \gamma-\mathrm{Fe}_{2} \mathrm{O}_{3}$, and $\mathrm{HCl}$ on mercury transformations in a $7 \mathrm{~kW}$ coal combustion system. Fuel Process Technol, 2005, 86: 429-448

10 Feng X, Tang S, Li Z, et al. Landfill is an important atmospheric mercury emission source. Chinese Sci Bull, 2004, 49: 2068-2072

11 Presto A A, Granite E J, Karash A. further investigation of the impact of sulfur oxides on mercury capture by activated carbon. Ind Eng Chem Res, 2007, 46: 8273-8276

12 Widmer N C, Cole J A, Seeker W R, et al. Practical limitation of mercury speciation in simulated municipal waste incinerator flue gas. Combust Sci Technol, 1998, 134: 315-326

13 Hall B, Schager P, Weesmaa J. The homogeneous gas phase reaction of mercury with oxygen, and the corresponding heterogeneous reactions in the presence of activated carbon and fly ash. Chemosphere, 1995, 30: 611-627

14 Luo Z, Hu C, Zhou J, et al. Stability of mercury on three activated carbon sorbents. Fuel Process Technol, 2006, 87: 679-685

15 Presto A A, Granite E J. Survey of catalysts for oxidation of mercury in flue gas. Environ Sci Technol, 2006, 40: 5601-5609

16 He S, Zhou J, Zhu Y, et al. Mercury oxidation over a vanadia-based selective catalytic reduction catalyst. Energy Fuels, 2009, 23: 253-259

17 Granite E J, Pennline H W, Hargis R A. Novel sorbents for mercury removal from flue gas. Ind Eng Chem Res, 2000, 39: 1020-1029 